\title{
Educação a distância na formação profissional continuada de professores da educação básica: analisando contratos e destratos didáticos a partir de um estudo de caso
}

\section{Distance education in the continuing professional training of basic education teachers: analyzing didactic agreements and disagreements from a case study}

\author{
Gilberto Lacerda Santos ${ }^{1}$
}

\begin{abstract}
RESUMO
Os conceitos de contrato e de destrato didáticos foram desenvolvidos por Lacerda Santos e Iunes (2013), em uma investigação sobre aspectos que facilitam a relação entre informática e educação - os chamados contratos didáticos - e sobre aqueles que dificultam o estabelecimento de tal relação - os chamados destratos didáticos. Neste texto, apresentamos uma discussão baseada nos resultados de uma observação participante de uma situação educativa virtual na qual contratos e destratos didáticos foram relacionados com indicadores de inclusão e de fluência digitais de professores da educação básica, condições imprescindíveis para o sucesso de toda e qualquer ação de formação profissional continuada mediada pelas Tecnologias Digitais de Informação, Comunicação e Expressão (TDICE). Trata-se do relato de um estudo de caso em que professores experientes e digitalmente incluídos foram colocados em situação de alunos de um curso de especialização a distância. As conclusões do estudo indicam a existência de um cenário ainda preocupante para a implantação de cursos de formação continuada em serviço, que têm a inclusão e a fluência digitais como prerrequisitos para o
\end{abstract}

DOI: $10.1590 / 0104-4060.36096$

1 Universidade de Brasília. Faculdade de Educação. Brasília, Distrito Federal, Brasil. Campus Universitário Darcy Ribeiro. CEP: 70910-900. 
funcionamento dos cursos. Ressaltam-se também as dificuldades prementes na promoção da inclusão digital de professores, especialmente daqueles já engajados no mercado de trabalho, no exercício da profissão.

Palavras-chave: inclusão digital de professores; educação a distância; formação continuada de professores.

\begin{abstract}
The concepts of didactic agreements and disagreements were developed by Lacerda Santos and Iunes (2013), in an investigation on aspects that facilitate the relationship between information technology and education - the so-called didactic agreements - and on those which hinder the establishment of such relationship - the so-called didactic disagreements. In this paper, we present a discussion based on the results of a participant observation of a virtual educational situation in which didactic agreements and disagreements were used as indicators of digital inclusion and fluency of basic education teachers that are essential conditions for the success of any action of continuing professional training mediated by Digital Technologies of Information, Communication and Expression (TDICE). This is the report of a case study in which experienced and digitally included teachers became students in a graduate distance education course. The findings indicate the existence of a still worrying scenario for the deployment of continuing education courses in service that have digital inclusion and digital fluency as prerequisites to run. They also point out the pressing difficulties in promoting digital inclusion of teachers, especially those already in service, in the course of their work.

Keywords: teachers digital inclusion; distance education; teachers continuing education.
\end{abstract}

\title{
$O$ contexto do caso estudado
}

Em 2001, o Plano Nacional de Educação (PNE), aprovado na Lei n ${ }^{\circ} 10.172$, destacou a importância do princípio da gestão democrática e participativa no ensino público, o que colocou em destaque o papel do gestor no desenvolvimento de novas capacidades na formação inicial e continuada. Dentre as ações decorrentes do PNE, o Programa Nacional Escola de Gestores da Educação Básica Pública tem o objetivo de desenvolver uma política de formação nacional de gestores escolares, baseada no princípio citado, tendo por eixo a escola como espaço de inclusão social e da emancipação humana (BRASIL, 2009). O Programa Nacional Escola de Gestores foi iniciado como projeto piloto em 
2005, sob a coordenação do Instituto Nacional de Estudos e Pesquisas Educacionais Anísio Teixeira, e é ofertado pelo Ministério da Educação (MEC) em parceria com instituições federais de ensino superior de todo o Brasil. O curso de Especialização em Gestão Escolar é uma das ações do Programa e consiste em um curso de 400 horas, oferecido a distância por meio da plataforma Moodle e empregando estratégias e abordagens de e-learning. As relações educativas que ali ocorrem constituem um excelente exemplo de virtualização da escola, de migração docente rumo à sala de aula virtual e são baseadas em uma significativa exploração de Tecnologias Digitais de Informação, Comunicação e Expressão (LACERDA SANTOS; ANDRADE, 2010; LACERDA SANTOS, 2011). Assim sendo, o formato geral do curso pressupõe implicitamente uma inclusão digital básica e prévia por parte de seu público-alvo, isto é dos professores-gestores alunos do curso. De fato, a estes últimos se demanda apenas que disponham de acesso a computadores conectados à Internet, como uma espécie de fator de atestação da referida inclusão digital. É importante frisar que esse mesmo pressuposto pode ser identificado em um vasto leque de políticas públicas semelhantes, que utilizam a educação a distância por meio de TDICE como estratégia didática e que não oferecem aos alunos uma formação prévia para que compreendam e explorem estas novas tecnologias como meios de ensino e de aprendizagem. Ora, no caso do curso analisado neste texto, as duas turmas que já foram oferecidas apresentaram particularidades que apontam para uma grande inadequação entre o público-alvo e a dinâmica geral do curso. A primeira turma, embora tenha tido um alto índice de conclusão, foi objeto de uma imensa flexibilidade por parte dos tutores, a fim de permitir que a maior parte dos alunos concluísse a especialização. A segunda turma, com uma estratégia diferente de tutoria, foi iniciada com 385 alunos e concluída com apenas 105, de modo que apenas $27 \%$ dos gestores lograram êxito na formação. Temos aí configurada uma situação que merece um olhar investigativo, o qual foi objeto de um empreendimento de observação participante ao longo das duas turmas do curso, no formato oferecido pela Universidade de Brasília (UnB), cujos resultados são relatados neste texto.

\section{Metodologia de investigação}

Delimitada por diversos princípios evocados por Correia (2009), a observação participante empreendida, de natureza descritiva, foi realizada sem que os atores estivessem cientes da intenção investigativa, o que foi possível 
graças à situação educativa configurada pelo ambiente virtual de aprendizagem e pelas salas de aula virtuais que deram forma ao curso. É fato que ainda existe a necessidade de delimitar esta técnica no contexto do meio virtual, em que a telepresença dos atores, sem que um "veja" o outro, cria novas situações e possibilidades (AMARAL, 2008). No entanto, na busca por referenciais para subsidiar a ação investigativa, recorremos a elementos da abordagem proposta por Serrão e Lacerda Santos (2008) com a finalidade de considerar o conteúdo dos fóruns de discussão como relatos de campo. O produto da observação participante, realizada nos anos de 2010 e 2011, será apresentado e discutido de acordo com nove categorias, que foram evidenciadas ao longo da observação: prontidão no acesso às salas de aula virtuais, engajamento nas discussões, pertinência das contribuições, quantidade de interações, capacidade de acompanhar discussões, capacidade de gestão do próprio tempo, capacidade de manuseio de ferramentas virtuais, dinâmica da atividade e dinâmica da interatividade.

\section{Educação a distância mediada por TDICE e a inclusão digital de professores da educação básica}

A educação a distância (EaD) mediada por TDICE consiste em praticamente uma nova modalidade de $\mathrm{EaD}$, com estrutura e modo de funcionamento totalmente distintos daqueles que caracterizaram as primeiras iniciativas nesse campo, baseadas no uso do material impresso como suporte didático e no uso do correio postal e de meios físicos como suportes comunicacionais. Como foi apontado na dissertação de mestrado de Garonce (2003), a evolução da EaD acompanhou a evolução das tecnologias de informação, comunicação e expressão, de modo que o advento da Informática gerou um novo e promissor cenário para acolher situações de ensino e aprendizagem que têm o material digital como suporte didático e o uso do correio eletrônico e da Internet como suportes comunicacionais. Esta nova modalidade de educação a distância, por ser estruturalmente alicerçada em novas tecnologias, demanda habilidades e competências diferenciadas de seus usuários, que necessitam lidar com as TDICE. Essas tecnologias novas impõem um novo modo de funcionamento do sujeito, justamente por delimitarem um novo modo de funcionamento da sociedade. Esse novo modo perpassa e modifica as estratégias de busca e processamento de informações, de estabelecimento de comunicações e de possibilidades de expressão, enfatizando o papel das TDICE como verdadeiras extensões do homem, como anteviu McLuhan (1964). Consequentemente, este novo modo de funcionamento perpassa e modifica os nossos modos de ensinar e de aprender. 
Nesta perspectiva, a EaD mediada por TDICE só se torna viável face ao cumprimento de dois tipos de requisitos. Por um lado, é necessário todo um aparato tecnológico, suprido por dispositivos materiais de acesso ao mundo da Cibercultura (computadores, tablets, smartphones etc., conectados à Internet). Por outro lado, é necessário todo um aparato cognitivo, suprido por dispositivos imateriais necessários para o manuseio das informações e dos conhecimentos que caracterizam a Cibercultura (competências, habilidades e atitudes específicas para a exploração autônoma e crítica das TDICE). Enquanto os dispositivos materiais são facilmente supríveis, conforme atestam inúmeras iniciativas do poder público brasileiro, como o Programa Nacional de Informática na Educação (PROINFO) ou o projeto Um Computador por Aluno (UCA), os dispositivos imateriais dependem de mudanças culturais e de iniciativas de qualificação da educação básica oferecida a toda a população. Em outras palavras, para que um indivíduo possa acessar um computador conectado à Internet e fazer um curso a distância, é preciso muito mais do que apenas acessar o computador. É preciso que ele seja capaz de mobilizar-se em torno de determinadas dinâmicas de consumo, produção e compartilhamento de conhecimentos, possibilitadas por competências, habilidades e atitudes que o permitam informar-se, comunicar-se e expressar-se no ambiente da Cibercultura ou da Sociedade de Colaboração em Massa ou da Sociedade em Rede.

Estas novas dinâmicas de consumo das TDICE caracterizam profundamente a EaD contemporânea enquanto manifestação da Cibercultura e com foco nas migrações docentes para a sala de aula virtual, como apontaram Lacerda Santos e Andrade (2010). A qualidade da EaD mediada por TDICE é, portanto, diretamente proporcional à qualidade da inclusão e da fluência digitais dos atores das relações educativas virtuais, aos quais se demandam competências, habilidades e atitudes qualitativamente diferentes daquelas requeridas pela sala de aula convencional: autonomia, criatividade, interatividade, colaboração, compartilhamento, concisão, engajamento, pertinência, autogestão, entre outras. No entanto, e de acordo com as observações de Prensky (2001), é muito comum encontrarmos esse perfil nos estudantes, de modo geral alinhados na classificação de "nativos digitais" e nos quais a fluência digital é um fato consumado. Já nos professores, normalmente alinhados na classificação de "imigrantes digitais", esse perfil ainda é raro e a fluência digital se configura como uma possibilidade nem sempre consumada. Isto porque são patentes as dificuldades na promoção da inclusão digital de professores da educação básica, as quais têm sido apontadas por vários pesquisadores tais como: Carvalho e Pocrifka (2010), que estudaram os processos de apropriação, por professores pernambucanos, dos laptops distribuídos pelo projeto UCA; Souza (2010), que realizou uma investigação participante sobre a cultura digital e a formação de professores por 
meio do Projeto Tabuleiro Digital, desenvolvido na Universidade Federal da Bahia; Ferreira (2009), que também lançou luzes sobre a situação da inclusão digital de professores da Secretaria de Educação do Distrito Federal por meio da verificação do cumprimento dos objetivos dos projetos decorrentes de políticas públicas de promoção da inclusão digital desses profissionais; e Roseli Lopes (FUNDAÇÃO VICTOR CIVITA, 2010), que mostrou, a partir de investigação realizada em 400 escolas públicas em 13 capitais brasileiras, que o tradicional problema de falta de infraestrutura está sendo superado pela falta de preparo para lidar com as novas tecnologias por parte dos professores. Ora, se os professores da educação básica, de modo geral, estão distanciados dos patamares desejados de inclusão e de fluência digitais, como supor que eles venham a angariar bons resultados em iniciativas de sua própria formação continuada, quando estas iniciativas se baseiam justamente na inclusão e na fluência digitais como meios de aprendizagem em situações de educação a distância? Essa questão está na base da investigação relatada neste texto, cujos resultados são apresentados a seguir, por meio da análise das categorias que nortearam a observação participante que delimitou o estudo de caso.

\section{TDICE e professores: contratos e destratos}

No contexto das duas turmas já oferecidas no Curso de Especialização em Gestão Escolar, campo empírico desta investigação, os participantes se situaram em salas de aula virtuais gerenciadas por professores e conduzidas por tutores. A estes últimos coube a dinamização das relações educativas em torno dos objetivos de aprendizagem visados pela formação. As observações realizadas em 50 fóruns de discussão entre tutores e alunos foram realizadas à luz das categorias descritas a seguir, elaboradas a partir do próprio modo de funcionamento do curso e das demandas regularmente endereçadas aos alunos.

\section{Categoria 1: Prontidão no acesso às salas de aula virtuais}

A categoria "prontidão no acesso às salas de aula virtuais" foi adotada para se medir o tempo decorrido entre o início das atividades do curso e o primeiro acesso de cada participante-aluno. Nas duas turmas isso ocorreu de modo distinto. Na primeira turma, como houve um processo de familiarização inicial com a Plataforma Moodle, o tempo de acesso foi menor, mas ainda assim curiosamente longo se considerarmos que todos os alunos tinham, em teoria, 
acesso a computadores conectados à Internet. Nesse caso, foram necessárias três semanas para que todos os alunos acessassem o ambiente virtual. Já no caso da segunda turma, o primeiro acesso demandou muito mais tempo, uma média de cinco semanas. Analisado sob a ótica dos contratos e dos destratos didáticos, esse cenário, tanto em uma turma quanto na outra, anuncia a existência de dificuldades no acesso ao computador e, portanto, na maneira como as relações educativas do curso haviam sido preconizadas. Já tínhamos aí um primeiro indicador da desconexão entre os participantes-alunos e a proposta do curso. No mínimo, já se poderia concluir que apenas o acesso a computadores conectados à Internet não foi condição suficiente para que os alunos participassem do curso, ou pelo menos para que estivessem presentes nas salas de aula virtuais.

\section{Categoria 2: Engajamento nas discussões virtuais}

A categoria "engajamento nas discussões virtuais" colocou em evidência o modo como os alunos se inteiravam dos temas em debate ou dos assuntos em pauta e como neles se engajavam. É importante lembrar que os participantes do curso eram professores experientes, digitalmente incluídos e no exercício de funções de gestão escolar. No entanto, uma vez colocados na situação de "alunos" e no contexto da virtualidade, ambas as turmas revelaram um cenário complicado. Por um lado, parte significativa dos alunos estava bastante distanciada do papel de estudante, com rotina de estudante, a qual requeria leituras e promoção de debates, suscitando interações pedagogicamente pertinentes. Por outro lado, a maior parte dos alunos jamais havia se servido da Internet como meio de aprendizagem, embora quase $100 \%$ tivesse trânsito no mundo virtual, por meio de redes sociais, blogs e uso de dispositivos diversos. Como foi mencionado antes neste texto, a primeira turma recebeu um tratamento tutorial muito flexível, a fim de permitir que a maior parte dos alunos concluísse a especialização. Já na segunda turma, uma estratégia diferente de tutoria foi aplicada, apostando mais na autonomia dos participantes e os resultados foram pífios. Decorre daí que o engajamento nas discussões virtuais teve uma relação direta com a atuação dos tutores nas diferentes turmas. Em suma, a consideração desta categoria revelou que a educação a distância mediada por TDICE, que adota novas pedagogias, requer, por parte dos alunos, uma sintonia fina com estas novas pedagogias, a qual é manifestada, sobretudo, por um engajamento efetivo nas ações didáticas no ambiente virtual, inquirindo, participando, colaborando e construindo conhecimentos de forma coletiva. Nas duas turmas, isto foi observado em uma parcela muito pequena de alunos, o que remete à necessidade de uma acurada análise de perfil de participantes de iniciativas desta natureza antes que as mesmas se constituam, se consolidem e avancem. 


\section{Categoria 3: Pertinência das contribuições}

A categoria "pertinência das contribuições" foi empregada para analisar o conteúdo das "falas" dos alunos do curso. É importante frisar que tais falas eram efetivadas de forma escrita, em fóruns de discussão virtual. Assim sendo, participar de discussões por escrito, no modo de funcionamento dos fóruns da Plataforma Moodle, requer estratégias, por parte dos atores, muito distintas daquelas empregadas em uma discussão oral. A discussão virtual escrita tem um rito particularmente complexo para que não se perca o foco, para que não se mude de assunto, para que se entenda o tema em discussão quando a mesma é acessada. Como nenhuma fala foi interrompida e os tutores nunca utilizaram suas prerrogativas de "apagar" contribuições não pertinentes, todos os fóruns foram caracterizados por um número importante de desconexões, digamos assim. Em todos eles, nas duas turmas, os alunos mais ágeis no manuseio da ferramenta e da linguagem eram perturbados por alunos que entravam nas discussões com outras discussões, com questões de outra natureza, que não se davam ao trabalho de ler o debate em curso para providenciar contribuições pertinentes, mas que não se furtavam de "contribuir" de qualquer maneira, como estratégia para registrar presença na sala de aula virtual. No andamento do processo de observação participante, essa categoria foi expressa por meio de uma quantificação percentual de contribuições pertinentes em cada discussão conduzida nos fóruns do curso. Tal tarefa tornou-se totalmente evasiva, tamanha a dificuldade dos tutores, de modo geral, em manter os alunos participantes dos fóruns (cerca de $40 \%$ nas duas turmas) engajados em discussões inequívocas e objetivas. De modo geral, muito além dos problemas decorrentes de deficiências na formação inicial dos alunos do curso, o problema da pertinência das contribuições localizou-se, a nosso ver, no distanciamento de hábitos de leitura sistematizada de conteúdos de natureza técnica, em problemas no manuseio da Língua Portuguesa como modo de expressão escrita e nas dificuldades de compreensão da complexidade de discussões, conduzidas nos fóruns virtuais. Tanto é que mais de $30 \%$ dos alunos se faziam presentes, sempre em silêncio, sem participar das discussões, supostamente apenas lendo as intervenções. A conclusão disto tudo é simples e clara: não se faz educação a distância mediada por TDICE, com a devida qualidade, sem se contar com alunos pertinentemente engajados nas discussões virtuais, o que demanda seja alunos com determinados perfis, seja alunos com formação prévia para usufruto pleno de tais relações educativas.

\section{Categoria 4: Quantidade de interações}

A categoria "quantidade de interações" permitiu, como seu enunciado o indica, a contagem sumária do número de interações feitas por cada participante, 
posto que a Plataforma Moodle dispõe de um recurso que permite tal contagem. Nas duas turmas, o resultado é impressionantemente alto. A maior parte dos alunos teve um número significativo de interações computadas, mesmo que tardias, as quais, no entanto e conforme indicou a categoria anterior, careciam, de modo geral, de pertinência, de sentido, de conexão e de engajamento. Que sinalizações decorrem deste cenário? Ora, o relato aqui encaminhado diz respeito a relações educativas virtuais, a situações de educação a distância, caracterizadas pela imaterialidade das ações educativas, do trabalho docente e da atuação dos estudantes. Todavia, trata-se de relações educativas e todos nós temos fortes representações acerca de como devem ser tais relações: alunos alinhados de um lado, ouvindo silenciosamente seus professores (em ocorrência, tutores), alinhados de outro; alunos em silêncio, com participações pautadas pela passividade, pela ordem na comunicação e expressão, pelo ritmo quase fabril de construção de conhecimentos. É muito visível como essa dinâmica é sumariamente transposta por todos para o ambiente virtual. No entanto, a imaterialidade da presença das pessoas na sala de aula virtual requer algum tipo de manifestação para se dizer "presente" ao professor, ao tutor e aos colegas. Então, uma quantidade significativa de interações é meramente protocolar, traduzida sob a forma de concordâncias vazias ou de mudanças de assunto ou de retomadas de elementos já ultrapassados na discussão. Enfim, a conclusão é clara: a quantidade de interações em relações de educação a distância mediada por TDICE não é indicador da qualidade das mesmas.

\section{Categoria 5: Capacidade de acompanhar discussões}

A “capacidade de acompanhar discussões” em fóruns de discussão virtual é uma categoria crítica e indicadora do sucesso da participação do indivíduo em relações educativas a distância. Talvez seja aí que se encontra o principal fator de conversão e de migração do concreto para o virtual, em se tratando de relações educativas. As discussões virtuais, quando pertinentemente conduzidas e pedagogicamente articuladas, colocam em colaboração todos os elementos que caracterizam ou que devem caracterizar a pedagogia digital: as inovações nos modos de se informar, de se comunicar e de se expressar em torno da construção coletiva de conhecimentos; a busca autônoma de informações suscetíveis de contribuírem com a qualidade das discussões e de agregarem valor ao que é ensinado e ao que é aprendido; a habilidade de se "domesticar" o enorme fluxo de informações ao qual o sujeito pode estar submetido em tal situação; a possibilidade de se expressar livremente, mas por meio de códigos escritos que são recebidos por todos os participantes e que em todos podem ter impacto. Dada sua complexidade, esta categoria foi o principal indicador de que as discussões 
virtuais que ocorreram no curso, em suas duas turmas, deixam ainda a desejar no que se refere ao alcance da dinâmica da Cibercultura. Analisá-las implica em se perceber que, de um modo ou de outro, estamos todos um pouco à deriva na organização do trabalho pedagógico virtual e na assunção de posturas docentes e discentes condizentes com a nova mídia. Mais do que um problema geracional, temos aqui um problema didático, cuja existência é claramente explicitada ao longo das duas turmas do curso: parece haver uma incapacidade generalizada em se conduzir e em se participar de fóruns virtuais de discussão de modo significativo, pertinente e alicerçado em novos modos de se informar, de se comunicar e de se expressar. Essa incapacidade caracterizou as interações nas duas turmas do curso.

\section{Categoria 6: Capacidade de gestão do próprio tempo}

Em um curso virtual, os atores da relação educativa estão distanciados e livres das amarras da sala de aula convencional, na qual todos têm que estar presentes ao mesmo tempo e funcionarem quase em uníssono, seguindo rituais já bastante ancorados em nosso imaginário. Um elemento fundador de um curso virtual é a necessidade de gestão do próprio tempo de dedicação à aula, dentro dos limites estabelecidos pelos professores e tutores. Situar-se em um cronograma e segui-lo animado por forças intrínsecas é uma capacidade que tem se mostrado bastante complexa no universo da educação a distância e que sempre é colocada em evidência, dada sua crucialidade. A análise desta categoria nas duas turmas do curso revelou a existência de grande dificuldade, por parte dos alunos, em gerir seu tempo de forma autônoma, o que gerou inúmeros atrasos e acumulações de atividades ao longo de todo o tempo de estudo. É claro que é necessário considerar o fato de que os alunos estavam em situação de formação profissional continuada, a distância e em serviço. Portanto, o tempo de dedicação ao curso era limitado. Entretanto, a dinâmica de funcionamento do mesmo, explicitada a todos, exigia o cumprimento de cronogramas, a realização de tarefas e a participação em atividades que uma vez realizadas não mais se repetiam. As próprias disciplinas tinham essa característica, posto que uma vez reprovados em uma delas, os alunos eram excluídos do curso pelo simples fato de que as disciplinas não se repetiriam, não havia modo de recuperação, professores e tutores contratados para tal oferta; eles não fariam uma segunda oferta. É sabido que existe um senso comum de que um curso a distância é um curso livre, aberto, sem limites de tempo e de espaço, sem rotinas, sem esforço, em que a imaterialidade é confundida com irresponsabilidade. Temos aí uma armadilha em que caem todos os que esperam lograr sucesso em um curso a distância de boa qualidade, sem se empenhar com seriedade. Temos aí 
uma situação bastante recorrente nas duas turmas do curso, o que fica claro nas verdadeiras súplicas dos tutores para que os alunos se empenhassem em seguir o ritmo da turma, em gerenciar o próprio tempo sem sair dos limites do tempo acordado a todos. A observação de elementos referentes a esta categoria aponta, sobretudo, o choque cultural decorrente da migração de relações educativas convencionais para relações educativas virtuais.

\section{Categoria 7: Capacidade de manuseio de ferramentas virtuais}

As relações educativas virtuais do Curso de Especialização em Gestão da Educação, além de usufruírem dos recursos da Plataforma Moodle, faziam constantemente apelo a ferramentas próprias para o percurso no Ciberespaço: a busca de conteúdos em sites de pesquisa, a leitura de artigos publicados em repositórios virtuais, discussões em chats, a visita a blogs e a sites, etc. Aí também os alunos do curso demonstraram, de modo geral, grandes dificuldades, posto que o acesso às novas linguagens de comunicação, informação e expressão não é desprovido de complexidades, mesmo sendo os sujeitos contumazes participantes de redes sociais e transeuntes na Internet de forma casual. Conforme já sugerido antes, o acesso a computadores e a esse nível de uso da rede não é condição para se avançar para seu aproveitamento com fins didáticos, em que se demanda atividade e interatividade por parte dos sujeitos. A incapacidade generalizada de manuseio de ferramentas virtuais por parte de um grande contingente de alunos indica a necessidade de uma prévia educação para a nova mídia antes de se avançar no uso efetivo da mesma. É como se o "aprender fazendo", que parece ser uma premissa desse e de outros cursos de educação continuada a distância, não fosse realmente efetivo, posto que se trata de um grande deslocamento cultural, que demanda novas e importantes mudanças de comportamento de todos os atores da relação educativa. Nesse caso, e ao contrário do que escreveu Clarice Lispector, a velocidade da mudança é tão importante quanto a direção da mudança. Em outras palavras, a EaD mediada por TDICE propõe novos paradigmas para se ensinar e se aprender, alicerçadas em uma dinâmica específica. Sem o domínio de tal dinâmica, seja adquirido previamente ou no decorrer do curso, os proveitos a se tirar da educação a distância mediada por TDICE são muito restritos. De modo geral, em nenhuma das duas turmas do curso aqui avaliado os alunos demonstraram plenamente esta capacidade de manuseio das ferramentas virtuais. Isto tornou as interações muito protocolares e burocráticas e bastante alinhadas com o cumprimento sumário dos objetivos de aprendizagem, sem que os participantes tenham ido beber nas fontes da hipertextualidade, do trabalho colaborativo, da autonomia e da criatividade. No caso da primeira turma, é importante frisar que relativo 
sucesso do empreendimento de elaboração de monografias só foi possível graças à adoção de uma metodologia que consistiu no preenchimento gradativo de uma espécie de formulário que estabelecia etapas pré-determinadas, por meio das quais a monografia ia tomando forma. Na segunda turma, em que tal metodologia não foi adotada, os alunos sentiram-se muito perdidos, sem referenciais e pouco apoiados no processo de pesquisa, primeiramente porque não detinham a cultura do pesquisador e, em seguida, porque não sabiam lidar com as TDICE que davam forma ao curso.

\section{Categoria 8: Dinâmica da atividade}

A categoria "dinâmica da atividade" diz respeito à forma como o aluno opera e transita no espaço virtual proporcionado pelo curso a distância. Em se tratando de salas de aula virtuais, caracterizadas pela imaterialidade do trabalho pedagógico e pela telepresença dos atores da relação educativa, a dinâmica da atividade do sujeito gira em torno de outros - e novos - rituais. Estes determinam como se dá o acesso e a participação nas situações de ensino, como se articula o "estar" em situação de aprendizagem e como é possível beneficiar-se dos insumos fornecidos pelos professores, pelos tutores e pelos materiais didáticos digitais em prol da construção de conhecimentos novos. Em uma situação de educação a distância mediada por TDICE, espera-se que os alunos, desde o início ou depois de algum tempo, sintam-se plenamente à vontade no domínio da virtualidade da situação, tanto nos momentos síncronos quanto nos momentos assíncronos, o que pode ser manifestado, entre outros, pelo cumprimento de categorias como a capacidade de manuseio das ferramentas virtuais, a pertinência das contribuições, o engajamento nas discussões virtuais e a quantidade de interações. Já vimos, na análise dessas categorias, que houve um aproveitamento fraco por parte dos alunos dos elementos delimitadores e decorrentes da situação educativa em que estavam envolvidos, donde conclui-se que os participantes foram, de modo geral, pouco ativos, isto é deficientes na dinâmica da atividade da EaD mediada por TDICE.

\section{Categoria 9: Dinâmica da interatividade}

A última categoria considerada na investigação, a "dinâmica da interatividade", diz respeito à forma como os alunos se comunicam com os professores, com os tutores e com os demais alunos. Na consideração desta categoria, a observação realizada evidenciou níveis baixos de interatividade nas interações entre alunos e tutores e insignificantes entre os alunos e seus pares. Nas duas turmas, especialmente na segunda, houve, por parte dos alunos, uma imensa 
penúria de intervenção colaborativa, de construção de sentidos autônomos e criativos, de diálogos construtivos e de reação aos estímulos dos tutores. Estes últimos, é importante frisar, tiveram que frequentemente recorrer a abordagens que extrapolavam a virtualidade, a fim de angariar participações e de provocar reações. Em suma, o curso, de modo geral, foi caracterizado por instituir situações inovadoras de $\mathrm{EaD}$ mediadas por TDICE acolhendo relações educativas mais próximas das convencionais, caracterizadas pela linearidade nas relações, pela falta de colaboração entre os alunos e pela baixa interatividade.

\section{À guisa de conclusão}

A observação participante das duas turmas do Curso de Especialização em Gestão da Educação, oferecido na modalidade a distância e com finalidades de formação continuada para gestores de escolas de educação básica pública do Distrito Federal e de seu entorno, permitiu que se pudesse elaborar diferentes constatações acerca do alunado do curso, de sua modalidade de oferta e, mais amplamente, sobre categorias que dimensionam o conceito de fluência digital e sobre a educação a distância mediada pelas novas tecnologias de informação, comunicação e expressão. Por fim, foi possível tecer considerações acerca dos contratos e destratos didáticos que, na perspectiva aqui adotada, caracterizaram as relações educativas que delimitaram o curso.

No que se refere ao alunado, a investigação colocou em evidência seu despreparo geral para usufruir adequadamente de um curso de EaD mediado por TDICE, em que competências, habilidades e atitudes específicas são demandas dos atores das relações educativas. Com uma formação profissional inicial deficiente e estando há muitos anos longe dos "bancos da escola", os professores-gestores participantes do curso apresentaram, sempre de modo geral, muitas dificuldades para manterem-se engajados e para lograrem êxito na formação, especialmente devido a dificuldades de manipulação das novas linguagens decorrentes das TDICE. Ora, o curso observado não tem o objetivo de promover a inclusão digital dos professores, mas a tem como pré-requisito não declarado. Assim sendo, os formuladores de políticas públicas devem levar em conta a inclusão e a fluência digitais efetivas dos atores como condição prévia de participação em atividades formativas semelhantes.

Com relação à modalidade de oferta do curso, a observação da evolução do alunado ao longo da formação indica que a escolha da educação a distância como estratégia formativa pode consistir em uma espécie de "tiro no próprio 
pé", tendo em vista que o usufruto pleno de salas de aula virtuais, concebidas como componentes da Cibercultura, demanda conhecimentos, habilidades e atitudes cujo desenvolvimento não é simples, especialmente em se tratando de professores de educação básica pública de nosso país. Sem dúvida, o emprego de tal modalidade permite que, de um modo ou de outro, se atinja um grande contingente de alunos, espalhados no território, e que se nutra as estatísticas governamentais com números que indicam a superação de diversos problemas crônicos no cenário educativo nacional. Mas, onde fica a qualidade da formação? No Distrito Federal, dadas suas reduzidas dimensões geográficas, várias medidas foram tomadas pelos professores e tutores para sanarem dificuldades dos alunos e para que eles fossem diretamente abordados, em encontros presenciais. E em estados imensos como o Maranhão, o Tocantins e ou a Bahia, nos quais, em caso de pane, não se pode convidar os alunos para comer uma pizza com os tutores e discutir o trabalho em realização, que situação fica configurada?

Com relação às categorias que emergiram das observações, constata-se que elas qualificam o conceito de fluência digital, ao mesmo tempo em que o tornam mais complexo. Mais que um componente da inclusão digital, que se refere ao acesso a dispositivos informáticos conectados à Internet, a fluência digital, que se refere às condições plenas de informação, comunicação e expressão por meio de tais dispositivos, demanda, de fato, que os indivíduos sejam capazes de participar de relações educativas virtuais com prontidão, engajamento, pertinência, intensidade, gestão, habilidade, atividade e interatividade, sob pena de não lograrem êxito nas situações formativas virtuais a que forem submetidos. É importante também se distinguir fluência digital, especialmente quando há finalidades educativas em jogo, de uso da Internet no cotidiano, em redes sociais, normalmente plenas de atividade e vazias de interatividade e de processos de construção de conhecimentos.

Por fim, fica evidente que, na formação aqui analisada, contratos didáticos foram flagrantemente quebrados, dando lugar a destratos que geraram desmotivação não somente aos alunos, mas também aos professores e, sobretudo, aos tutores. A maior parte destes destratos se materializa justamente nas categorias de análise das interações dos alunos com o curso, as quais, na verdade, foram implicitamente consideradas como pontos pacíficos junto a professores apresentando, de modo geral, deficiências em sua formação inicial e em sua inclusão digital. A impressão que fica é que seria necessária uma calibragem na formação, a fim de que ela cumpra melhor seus objetivos de formação profissional a distância em serviço, sem deixar sequelas em seus participantes. 


\section{REFERÊNCIAS}

AMARAL, A. Autoetnografia e inserção online: o papel do pesquisador-insider nas práticas comunicacionais das subculturas da Web. Anais do XVII Encontro da Compós, São Paulo (SP), 2008. Disponível em: <http://www.fronteiras.unisinos.br/pdf/62.pdf>. Acesso em: 05/04/2012.

BRASIL, Ministério da Educação. Diretrizes Nacionais do Programa Escola de Gestores da Educação Básica Pública. Brasília: MEC, 2009.

CARVALHO, A. B. G.; POCRIFKA, D. H. O professor e o desafio do laptop em sala de aula: Reflexões sobre o Projeto Magalhães e o Programa Um Computador por Aluno. Anais do $3^{\circ}$ Simpósio Hipertexto e Tecnologias na Educação. Recife (PE): UFPE, 2010.

CORREIA, M. C. B. A observação participante enquanto técnica de investigação. Pensar Enfermagem, Lisboa (Portugal): Escola Superior de Saúde do Instituto Politécnico de Beja, v. 13, n. 2, 2009.

FERREIRA, M. Inclusão digital de professores da Secretaria de Educação do Distrito Federal: um estudo sobre a formação docente. Dissertação (Mestrado em Educação) - Programa de Pós-Graduação em Educação, Universidade de Brasília, Brasília, 2009.

FUNDAÇÃO VICTOR CIVITA. O Uso dos computadores e da Internet nas escolas públicas de capitais brasileiras. Relatório final. São Paulo (SP), 2010. Disponível em: $<$ http://www.fvc.org.br/relatorio-computores-internet.pdf>. Acesso em: 15/05/2012.

GARONCE, G. V. Estudo sobre a implantação e a evolução de um curso de educação a distância: o caso do Curso de Aperfeiçoamento de Oficiais da Aeronáutica. Dissertação (Mestrado em Educação) - Programa de Pós-Graduação em Educação, Universidade de Brasília, Brasília, 2003.

LACERDA SANTOS, G.; ANDRADE, J. B. F (Org.). Virtualizando a escola: migrações docentes rumo à sala de aula virtual. Brasília, Liber Livro, 2010.

LACERDA SANTOS, G.; FIRMINO, E. A. P. A inclusão digital de professores da educação básica: sinalizações para a compreensão de um problema complexo. In: LACERDA SANTOS, G. (Org.). Educação continuada a distância de gestores escolares: subsídios para avaliação de uma política pública. Brasília (DF): Liber Livros, 2012.

LACERDA SANTOS, G. Uma pesquisa longitudinal sobre professores e computadores. Educação \& Realidade, Porto Alegre (RS): UFRS, v. 36, p. 837-848, 2011.

McLUHAN, M. Os meios de comunicação como extensões do homem. Trad. Décio Pignatari. São Paulo: Cultrix, 1964.

PRESNSKY, M. Digital Natives, Digital Immigrants. In: PRESNSKY, M. On the Horizon. Bradford, West Yorkshire: MCB University Press, 2001. 
SERRÃO, R. M. R.; LACERDA SANTOS, G. A Construção de conhecimentos em fóruns virtuais de discussão: proposta de uma metodologia para análise de interações em situações de educação a distância. Anais do Encontro Nacional de Didática e Prática de Ensino. Porto Alegre (RS): EduPUCRS, 2008.

SOUZA, J. S. Cultura digital e formação de professores: possibilidades e vivências entre professores e formação. Dissertação (Mestrado em Educação) - Programa de Pós-Graduação em Educação, Universidade Federal da Bahia, Salvador, 2010.

Texto recebido em 08 de abril de 2014. Texto aprovado em 22 de abril de 2014. 